\title{
TEATRO PERIFÉRICO E UNIVERSIDADE: \\ sinais de uma epistemologia da margem no Rio de Janeiro ${ }^{1}$
}

\section{University and peripheral theater:}

\section{signs of an epistemology from the margins in Rio de Janeiro}

\section{Rosyane Trotta}

UNIRIO

Resumo: $O$ artigo se propõe a examinar as conexões entre periferia e universidade com o objetivo de refletir sobre as transformações a partir das ações afirmativas, na cultura e na educação, e sobre a possibilidade de uma epistemologia decolonial no campo do teatro. Tomamos como base de observação dos conjuntos teatrais Cia Marginal, Grupo Atiro, e produções acadêmicas da Escola de Teatro da UNIRIO que tratam do racismo epistemológico.

Palavras-chave: Teatro de grupo; Racismo; Epistemologia.

Abstract: The article proposes to examine the connections between periphery and university, to reflect on the transformations imposed by the affirmative actions and to consider the possibility of a decolonial epistemology in the theater field. As base of observation we analyze plays from the theatrical ensembles Cia Marginal, Grupo Atiro, and a few academic productions at UNIRIO School of Theater dealing with epistemological racism.

Keywords: Theater group; Racism; Epistemology.

1 Pesquisa realizada com o auxílio do edital INOVA 2017, da Diretoria de Inovação Tecnológica, Social e Cultural da UNIRIO. 
Antes de prosseguir, devemos relembrar que raças humanas não existem do ponto de vista genético ou biológico (PENA, 2005: 336).

Nos últimos anos, como professora da UNIRIO, venho sendo provocada pelas mudanças que a abertura dos portões da academia trouxe para a Escola de Teatro. Tendo como objeto de pesquisa a dramaturgia da cena, atuo junto a grupos em processos colaborativos. Nos últimos anos, a formação de coletivos dentro da universidade ou reunidos por artistas graduados me aproximou do teatro das periferias, tanto como dramaturga quanto como pesquisadora. Nesse artigo, procuro compartilhar algumas reflexões em torno das provocações trazidas pelo movimento decolonial.

No ano de 2017, o Centro de Letras e Artes da UNIRIO ganhou espaço nos jornais por manifestações de racismo, externadas de modo anônimo nas paredes da Escola de Teatro. As notícias, contudo, não informavam sobre outras pichações que, feitas durante a ocupação da universidade no ano anterior, faziam uma denúncia antecipada: "UNIRIO RACISTA". Em uma escola de arte, que enfrentou como pôde a ditadura militar e ergueu seu currículo programático sobre teorias críticas de esquerda e obras de cunho libertário, a acusação pareceu fora de contexto, sem bases reais. A que racismo se referiria?

Os centros de Letras e Artes, Ciências Humanas, Ciências Exatas e Tecnológicas, assim como a reitoria e as pró-reitorias da UNIRIO, estão situados na zona sul, a área mais privilegiada da cidade, a mais policiada, a melhor atendida pelos serviços públicos, a que concentra a vida cultural da cidade. As unidades, instaladas na avenida que leva à Praia Vermelha, estão a cem metros do acesso ao Pão de Açúcar, ponto turístico entre os mais visitados do país. Para chegar ao campus a partir das periferias, são necessários no mínimo dois meios de transporte, em um trajeto não inferior a uma hora e meia de duração. Já de Copacabana, é possível chegar em vinte minutos. Esse é apenas um elemento do quadro que fez com que a Escola de Teatro atendesse, desde sua fundação, uma juventude oriunda das classes privilegiadas, descendente de artistas, intelectuais e profissionais liberais.

Até muito recentemente a dramaturgia brasileira reproduzia, na distribuição de papéis que oferecia aos atores, a pirâmide social do país. Gerd Bornheim, que dedicou parte de sua produção à observação da cena brasileira, afirmava, no final de década de 1970, que o teatro...

... está embasado em toda uma
aparelhagem, desde a arquitetura
teatral até Tennessee Williams, que é
pertinente a uma classe e não poderia
ser generalizada: a burguesia, diz a
evidência, está longe de preencher as
condições fundamentais para
desempenhar o papel de uma classe
universal. (BORNHEIM, 1979, p. 137)

O filósofo tentava explicar porque a popularização do teatro não podia ser obtida com o aumento das casas de espetáculo, já que o exclusivismo da atividade não estava em sua distribuição, como se acreditava, mas em sua produção. Fenômeno semelhante se verificava na 
educação: na mesma época, apenas $2 \%$ da população brasileira ingressava na universidade. Embora na área da educação a questão pareça mais ligada ao acesso número de vagas e distribuição geográfica das escolas - enquanto no teatro ela compreende a representação social, o problema do acesso também está presente no teatro, assim como a questão da representação está presente da relação de ensino.

Em 1962, o Centro Popular de Cultura da UNE (CPC) produziu a peça "O auto dos 99\%", que tentava falar aos $99 \%$ de brasileiros excluídos da universidade - por acesso geográfico ou de disponibilidade de vagas. Na peça, representa-se a história do acesso à universidade por meio de títulos (de cidadão português, na Colônia; de nobreza, após a Independência; de latifúndio, após a República; de ensino médio em escola particular, de preferência estrangeira, no início do século XX). Depois, passa-se a retratar aulas de uma universidade. Na aula de Economia, o professor, que sai do sarcófago para lecionar, ensina: "O homem tem que lucrar. Não importa sobre o que, nem sobre quem". Sob forma de escárnio, os autores sugerem que a sala de aula era ocupada por filhos de empresários.

Entre 2003 e 2015, diversas leis de inclusão social entraram em vigor no Brasil (entre elas: consciência negra, 2003; Maria da Penha, 2006; propriedade da mulher sobre o imóvel do programa Minha Casa Minha Vida, 2009; igualdade racial, 2010; cotas na universidade, 2012; criminalização da homofobia, do racismo e do feminicídio, 2015) com o objetivo final de mudar o perfil de uma sociedade cujo Congresso Nacional precisou debater a lei de cotas por dez anos antes de aprova-la e onde o candidato à presidência melhor pontuado nas pesquisas de intenção de voto afirma sua disposição em acabar com ela. A fragilidade das ações governamentais de desenvolvimento social e humano em nosso país permite constatar a existência de uma parcela minoritária, mas economicamente poderosa, politicamente influente e socialmente manipuladora, a quem não interessam mudanças e, por isso, interessa manter a centralização.

O quadro retratado pelo CPC permanece relativamente estável até 2012 , quando a lei 12711 levou outro alunado para as salas de graduação do ensino público federal. $O$ corpo docente permanece composto por brancos, em proporção superior a $99 \%$ (CARVALHO, 2005), já que um professor universitário leva dez anos para ser formado - da graduação ao doutorado. Por mais que tenha sido empreendido um alto investimento para renovar o corpo docente, sua origem étnica e social não foi alterada - o que colocou os novos alunos diante de professores brancos. E das epistemologias do norte (SANTOS, 2009). A relação de colonização parece, então, se perpetuar. $O$ conflito que emerge dentro da sala de aula não se alimenta de longínquas referências históricas de escravização: ele se alimenta cotidianamente da violência a que os jovens negros da periferia estão submetidos. Os estudos do IBOPE e do IPEA para o Atlas da Violência vem 
apontando de modo contínuo que essa faixa geográfica e étnica da população tem estatísticas de genocídio. E o genocídio, como mostra Buenaventura de Souza Santos, costuma vir acompanhado historicamente do epistemicídio: eliminamse tanto os povos quanto seus conhecimentos e práticas sociais (SANTOS, 1995: 328), tanto os corpos quanto sua subjetividade. Comprovada a inexistência biológica da categoria de raça, revela-se sua construção:

Porém, mesmo não tendo o conceito de raças nenhum embasamento biológico, ele continua a ser utilizado, enquanto construção social, como forma de privilegiar e diferenciar culturas, línguas, crenças e grupos diferentes, os quais, na maioria das vezes, têm também interesses econômicos muito diferentes (...). (PENA, 2005, p. 336)

Nos movimentos sociais contemporâneos, especialmente os que se referem a etnia e a gênero, as diferenças recusam a inclusão pela assimilação da semelhança e marcam sua "desidentificação" (BUTLER, 2013). Os diversos movimentos da heterogeneidade se encontram na crítica à violência operada pela produção de homogeneidade e na afirmação de que, negados o saber, a cultura, o corpo, está se negando o direito à humanidade. A judia Judith, personagem de Brecht, só percebe esta operação quando se torna seu alvo:

Nestes últimos tempos eu tenho pensado muito numa coisa que há alguns anos você repetia sempre: que havia indivíduos de valor e outros de menor valor, e que, em caso de diabetes, uns teriam direito à insulina, outros não... $E$ eu concordava, de imbecil que eu era! Agora eles estabeleceram uma nova classificação desse tipo, e eu hoje estou entre aqueles que têm valor inferior a zero. $\mathrm{Eu}$ bem que mereci isso! (BRECHT, "Terror e Miséria no Terceiro Reich")

Embora o mundo ocidental tenha conferido ao holocausto que dizimou seis milhões de judeus o status de maior tragédia histórica da modernidade, a dizimação cotidiana com base na valoração do humano se verifica como produção contínua e incontável de vítimas, sem guerra. O elemento heterogêneo recebe "marcas de abjeção" (RISCADO, 2018) e, nesse processo, a ciência confere objetividade à normatização. (Importante considerar que a definição de homogeneidade não se define por uma suposta maioria que, pela expressão quantitativa, argumenta sua prioridade; a noção de minoria também se constitui pela construção ideológica da homogeneidade.)

Michel Foucault, em "A arqueologia do saber", diferencia saber e ciência. A ciência, localizada no campo do saber, age sobre ele, "estrutura alguns de seus objetos, sistematiza algumas de suas enunciações, formaliza alguns de seus conceitos e de suas estratégias" (FOUCAULT, 2008: 207). O estudo sobre a ciência, pelo viés foucaultiano, consiste na análise das práticas discursivas que a originam e das relações entre elas, para identificar as regularidades dos discursos científicos - e, por meio das recorrências, identificar sua historicidade. A episteme interroga a ciência, tomando-a como prática histórica que se constitui como produção de enunciados. 
Estudar o funcionamento ideológico de uma ciência para fazê-lo aparecer e para modificá-lo (...) é colocá-la novamente em questão como formação discursiva; é estudar não as contradições formais de suas proposições, mas o sistema de formação de seus objetos, tipos de enunciação, conceitos e escolhas teóricas. É retomá-la como prática entre outras práticas. (FOUCAULT, 2008, p. 208)

Dentro da universidade, especialmente de uma escola de artes, a convivência entre diferenças desiguais encontra um corpo discente parcialmente formado pelos movimentos sociais. A percepção de que 0 racismo está presente na epistemologia e no espectro étnico-social do corpo docente configura um novo movimento estudantil. No final de 2017, na Escola de Teatro, duas monografias de conclusão e um projeto de mestrado se dedicam à abordagem do racismo, referenciando-se, entre outros, na autora Grada Kilomba:

Não há discursos neutros. Quando acadêmicos brancos reivindicam um discurso neutro e objetivo, eles não reconhecem 0 fato de que eles também escrevem de um lugar específico que, certamente, não é neutro, nem objetivo, nem universal, mas dominante. É um lugar de poder. (KILOMBA, 2016, p. 32)

O ensino do teatro na universidade, enraizado no modelo ocidental europeu branco burguês como parâmetro universal e critério para a produção de conhecimento, começa a enfrentar questionamentos. Ao universal, geral e objetivo, contrapõe-se uma epistemologia que inclui o histórico, particular e subjetivo, "para que possamos todos juntos falar de um espaço, lugar e tempo específicos, de uma realidade e história específicas" porque "a teoria é sempre localizada em algum lugar, sempre é escrita por alguém" (KILOMBA, 2016: 32).

Assim procede a dissertação "Corpo Negro Feminino: ressignificação em performances de mulheres negras", cujo Capítulo II consiste na análise do solo "Lotus", de autoria da pesquisadora. $\mathrm{Na}$ introdução, Danielle Anatólio, depois de relatar que foi a primeira estudante a ingressar no Programa de Pós-Graduação em Artes Cênicas pelo sistema de cotas, após reinvindicação do cumprimento da lei, descreve experiências de racismo sofridas na universidade:

A temática que agora pesquiso ganhou força durante 0 processo seletivo para o Mestrado da UNIRIO Universidade Federal do Estado do Rio de Janeiro -, quando percebi que, dentro da universidade, meu corpo recebia diferentes olhares de estranhamento e isto, sem dúvidas, está relacionado à resistência que existe sobre a entrada de negros (as) através das políticas de ações afirmativas em espaços acadêmicos. (ANATÓLIO, 2018, p. 20)

No espetáculo "Arame Farpado", apresentado em 2017, na mesma Escola de Teatro, alunos periféricos testemunham a experiência de exclusão na universidade. $\mathrm{Na}$ dramaturgia, criada coletivamente, atores e diretor tratam da falta de espaço para a cultura popular, negra e brasileira, ancestral e contemporânea, e evidenciam o 
processo pelo qual uma determinada racionalidade se sobrepõe a outras formas de percepção, de pensamento, de formulação, de narrativa, de linguagem, como se sobrepõe ao corpo e demais formas de conhecimento. A cena 15, intitulada "Raincoast", sintetiza algumas questões de ordem ética e didática por meio da caricatura de uma professora:

- A era vitoriana. A rainha Vitória maravilhosa. Era a época dos figurinos mais lindos, o seu reino tinha muita paz, não tinha confusão, não tinha conflito, e não vai voltar nunca mais. (...) Eu fui a Londres assistir uma peça e caia uma chuva torrencial. E eu estava com meu sapatinho todo feito a mão. $E$ eu não podia deixar molhar de jeito nenhum. Não mesmo. Então eu fui na loja e comprei um raincoast. (...) Saí maravilhosa pro Globe Theatre. Cheguei seca. $O$ sapato intacto. Assisti uma peça maravilhosa. Isso é pra explicar pra vocês que é importantíssimo sair do Brasil. Vocês têm que viajar (...), aprender outras culturas e trazer pra cá.

A caricatura é explícita, sublinhando o eurocentrismo, o aburguesamento, a aculturação, em uma fala fútil que se pretende pedagógica. Na tentativa de fazer uma analogia, invertendo 0 saber valorizado pelo conteúdo programático, a produção distribui aos espectadores, antes do início do espetáculo, uma prova de cinco questões de múltipla escolha para testar seus conhecimentos em cultura popular periférica. Depois da cena "Raincoast", projetam-se na parede ao fundo do palco algumas provas, dando preferência àquelas assinadas pelos professores presentes, a maioria com nota zero e sobre as quais se fazem os seguintes comentários:

- Não saber que Jardim Palmares fica em Paciência é muito complicado. Você precisa sair da UNIRIO, expandir, não dá pra se fechar no mundinho da universidade e achar que é suficiente. Tem muito mais por aí afora. (...)

- Pelo amor de Deus. Na Maré tem tudo, querido. Ciclovia, escola de dança, companhia de teatro e museu. Como este tipo de erro pode ainda acontecer? Aqui é uma universidade federal. Quem paga é a população, então você deveria usar com sabedoria e não de qualquer jeito.

A plateia assovia e aplaude. Os raros professores presentes se constrangem. Embora criado para um contexto muito específico, "Arame Farpado" foi selecionado para se apresentar no Festival Cena Brasil Internacional e, em seguida, no projeto de circulação Palco Giratório, do Sesc de Santa Catarina - o que evidencia que a questão abordada não se restringe ao contexto para o qual o espetáculo foi criado. Na cena 16, intitulada "Nosso lugar de fala", o ator João Pedro Zabeti se dirige ao professor:

- Será que você não percebe o quanto esse lugar me exclui? Você me exclui, sua metodologia me exclui (...). Esse tipo de avaliação é pautado no século XIX e a gente está no século XXI e eu tô muito assustado. Muito assustado. (...) Quando é que a gente vai construir isso juntos?

Depois, seguindo o mote da cena anterior, ele ensina ao professor algo que supõe que ele não sabe: 
- O mundo é muito maior do que a sua ementa! O mundo é muito grande. A gente vive no planeta Terra. Dentro do planeta Terra existe o Oriente e o Ocidente, culturas completamente diferentes. Dentro do Ocidente existem a América do Norte, a América Central e a América do Sul, culturas completamente diferentes também. Dentro da América do Sul, existe o Brasil, dentro do Brasil nós temos o Rio de Janeiro e, dentro do Rio de Janeiro, a gente tem o Rio de Janeiro, que, desculpa ser redundante, também tem muitas culturas. Por exemplo, nós temos a Lidiane [atriz do espetáculo], que mora em Palmares!

Manifestações semelhantes, verbais, escritas ou cênicas, vem sendo recorrentes na academia, em diversas oportunidades. Elas são acolhidas pela direção da escola, têm pauta no teatro, acesso a acervos, equipamentos e técnicos, voz no colegiado, além da participação de professores convidados para mesas de debate. Alguns projetos de extensão lidam diretamente com a questão, entre eles, Teatro na Prisão, Artes Cênicas em Extensão, Teatro em Comunidade, Intercâmbio UNIRIO. Em 2018, a sexta edição do Festival Integrado de Teatro da UNIRIO² (FITU), organizado e realizado pelos alunos, teve como tema Teatro e Periferia.

\section{Teatro na periferia}

Em qualquer utilização social da expressão 'raça' deve sempre ficar claro e transparente que ela não embute nenhuma divisão natural ou essencial da natureza humana.

(PENA, 2005: 336)

\footnotetext{
${ }^{2}$ Conf.: <www.youtube.com/watch?v=2VczEcuO8dc>
}

Em 2006, aos 16 anos, Wallace Lino participou da criação da Cia Marginal, sediada na Favela da Maré, grupo em que atua até hoje. Em 2010, ingressou na UNIRIO e, em 2014, ministrando uma oficina pela Cia Marginal, reuniu os alunos em torno de um projeto artístico do qual emergiu o Grupo Atiro, tema de sua monografia de conclusão do Curso de Licenciatura em Teatro, "O teatro como canal de ruptura do silenciamento":
(...) as condições em que os não brancos foram inseridos na sociedade contribuem para a formação das favelas do Rio de Janeiro. No entanto, deste cenário, emergem experiências como as do Grupo Atiro. Essas ações pulsam em todas as áreas periféricas da cidade, espaços historicamente marginalizados, que trazem em sua população herança da sobrevivência negra diante da cotidiana tentativa de extermínio da negritude neste país. Apesar de a favela não ser composta por negros em sua totalidade, a formação das favelas surge das ações, e da institucionalização do racismo no Brasil. (LINO, 2018, p. 28)

Ao tratar das recentes investigações do teatro contemporâneo, a pesquisadora Silvia Fernandes percebe que essas experiências "se processam numa relação corpo a corpo com o real, entendido aqui como a investigação das realidades sociais do outro e a interrogação dos muitos territórios da alteridade e da exclusão social no país" (FERNANDES, 2013: 6-7). A pesquisadora se refere a um teatro que, para tratar da exclusão, necessita se deslocar em direção ao outro. Refere-se, portanto, ao teatro que, gestado no seio 
das classes socialmente privilegiadas, olha para fora. Grupos da periferia são, eles próprios, a alteridade.

\section{GRUPO ATIRO}

\begin{tabular}{|c|c|}
\hline Início & 2016 \\
\hline Atores & $\begin{array}{c}\text { André Sousa, Bárbara Assis, } \\
\text { Gabriel Affonso, Gabriel } \\
\text { Horsth, João Paulo Rodrigues, } \\
\text { Kamyla Galdeano, Marcos } \\
\text { Diniz, Marllon Araújo, Matheus } \\
\text { Affonso, Paulo Victor Lino, } \\
\text { Romário Mello, Sol Targino } \\
(12)\end{array}$ \\
\hline Direção & Wallace Lino \\
\hline Abrigo & $\begin{array}{l}\text { Centro de Artes da Maré } \\
\text { (CAM) e Redes de } \\
\text { Desenvolvimento da Maré }\end{array}$ \\
\hline Histórico & $\begin{array}{l}\text { Depois de um ano de oficina, } \\
\text { criação e circulação do } \\
\text { espetáculo "Vai", baseado na } \\
\text { memória dos atores sobre a } \\
\text { vinda de suas famílias do } \\
\text { Nordeste para o Rio de } \\
\text { Janeiro, o grupo estreia com } \\
\text { "Família", primeiro quadro da } \\
\text { tetralogia "Agora sei o chão } \\
\text { que piso". Em 2017, apresenta } \\
\text { o segundo quadro, "Obedeça". } \\
\text { Em 2018, estreiam "Anticorpo" } \\
\text { e "Corpo Minado". }\end{array}$ \\
\hline Temas & $\begin{array}{l}\text { Negritude, favela, } \\
\text { homoafetividade }\end{array}$ \\
\hline
\end{tabular}

O Grupo Atiro elaborou o projeto Agora Sei o Chão Que Piso, estruturado em quatro espetáculos independentes (sob os temas sexualidade, família, trabalho e sonho), que tomam como fonte de pesquisa as memórias e vivências dos atores e das atrizes para abordar as opressões a que jovens favelados, negros, LGBTQ+, nordestinos, estão expostos desde a infância. A tetralogia foi criada através de um processo de pesquisa que incluiu debates e colaborações de diretores, dramaturgos, pesquisadores, grupos, coletivos e instituições. A cada espetáculo, o grupo dedica um longo mergulho em busca de uma dramaturgia própria, buscando a correspondência entre tema e linguagem. O quadro "Família", por exemplo, tem atuação de três homens negros amarrados entre si por cordas e cuja situação - a mãe sai do presídio e volta para casa onde moram seus dois filhos - se revela lentamente, em metáforas e meias palavras, enquanto assistimos, dentro do círculo formado pelas cadeiras do público, a imagens de tensionamento da corda nesses corpos atados. O espectador ainda está em busca de um sentido que parece difuso quando o texto lança um dardo de humor crítico: "Depois passou uma mulher branca (risos; para uma pessoa branca da plateia) $\mathrm{Ai}$, desculpa! Eu não tenho problema com gente branca, inclusive tenho parentes na família que são brancos." Aos poucos, o texto ganha sentido direto:

(para uma pessoa branca da plateia) Eu quero ver você ter classe com a polícia entrando na sua casa, dando na cara do seu irmão, destruindo suas coisas! Eu quero ver você não gritar tendo que ir reconhecer o corpo do seu filho dentro de um valão. (...) Fé eu tenho. Eu até sonho todo dia que um dia eu vou acordar num mundo melhor, onde eu possa olhar as pessoas de igual pra igual. Mas aí quando eu acordo, eu percebo que até a fé foi inventada como um jeito de nos silenciar, porque nossa voz incomoda muito mais que o tiro que nos mata. 
A partir do tema "Família", o que o grupo revela são os problemas que dilaceram os núcleos familiares, ou seja, as questões sociais, que não estão apenas na esfera do poder, mas ali mesmo, sentadas na plateia. "Obedeça", o segundo quadro da tetralogia, tem como eixo de linguagem um programa de auditório infantil, com a participação de crianças em jogos de referência sexual. Mais uma vez, o grupo parte de um tema genérico para denunciar uma violência específica. Em uma das cenas, uma menina brinca com a boneca usando-a como instrumento de prazer/poder/violência, e termina por destroça-la.

Em relação à Cia Marginal, da qual descende, o Grupo Atiro apresenta uma continuidade e uma ruptura: continuidade do teatro enraizado em sua geografia e em sua cultura, tendo na criação coletiva a modalidade chave para a construção da cena e da dramaturgia; ruptura em relação à noção de encenação e sua implicação para a estética da cena, a unidade da linguagem e a homogeneização dos corpos - praticada pela Cia Marginal. Vamos então examinar um pouco esse fenômeno teatral e o contexto político em que se engendrou.

A Cia. Marginal, fundada em 2006, no bairro da Nova Holanda, na Favela da Maré, sintetiza o fenômeno que ocorreu na cidade e, por sua singularidade e pioneirismo, tanto estético quanto político, deu origem a outras iniciativas, que a questionaram, como acontece sempre que uma manifestação se estabelece como representação cultural de um grupo social e, assim, como parâmetro artístico. O grupo se formou a partir de uma oficina que se estendeu por dois anos e encenou na comunidade seus primeiros exercícios. Em 2006, ano em que se formaliza o grupo e seu nome, Isabel Penoni, com formação em teatro e em antropologia, começa a dirigir o primeiro espetáculo. Trata-se de uma mulher branca, de classe média, moradora da área geográfica mais privilegiada da cidade, à frente de um grupo composto por jovens negros que cursam o ensino médio da rede pública, moradores da Maré, de famílias com dificuldades de pagar as contas da casa. Os espetáculos são criados a partir da investigação da realidade, da memória, da subjetividade e da pesquisa de seus atores sobre o lugar onde habitam. Penoni, ligada a movimentos sociais, almeja para seus pares a apropriação dos meios de produção do teatro:

Desde 2005, a Cia. Marginal vem promovendo ações de enfrentamento à centralização da cultura no Rio de Janeiro, onde os equipamentos culturais estão concentrados nas zonas centrais da cidade e os moradores de espaços populares são, de maneira geral, excluídos desses equipamentos, não apenas como consumidores, mas também como produtores e difusores. (...) a Cia. Marginal pretende levar não apenas um novo tipo de teatro e de ator para os teatros da zona sul carioca, mas também um novo tipo de público, mais diverso e popular, contribuindo para a democratização do acesso à cultura na cidade. (trecho do projeto submetido à Secretaria Municipal de Cultura do Rio de Janeiro, em 2011) 
Entre 2007 e 2017, com a escrita contundente dos projetos e o registro legal fornecido pela ONG Redes de Desenvolvimento da Maré, o grupo foi contemplado por doze editais, para custeio de produção, circulação, pesquisa, formação e difusão. Os órgãos públicos de cultura - secretarias do município e do estado, FUNARTE e MinC - viabilizaram os projetos do grupo. As empresas, públicas ou privadas, que patrocinam o teatro hegemônico, não tiveram nenhuma influência sobre seus caminhos.

Fenômeno semelhante se repete, com menor exuberância, em diversos grupos periféricos do estado. A Cia Código (município de Japeri, Baixada Fluminense, fundada em 2005) teve como apoiador mais frequente em seus treze anos de existência a Secretaria de Cultura do Estado, e pontualmente a Petrobrás Distribuidora e o SESC. O Grupo Bonobando (bairro da Penha, zona norte do Rio de Janeiro, fundado em 2014) nasce da residência artística subsidiada por edital da Secretaria Municipal de Cultura, e, nos anos seguintes, é contemplado com dois fomentos do mesmo órgão, para criação, montagem, apresentação e, posteriormente, para a segunda temporada de seu primeiro espetáculo. As ações do grupo estreante, que promove a iniciação e o desenvolvimento técnico e artístico da equipe, a formação de público, a descentralização da produção e da fruição teatral, se viabilizam pelo custeio direto da administração pública. E, assim como na Cia Marginal, a diretora do Bonobando, Adriana Schneider Alcure, tem formação em antropologia e integra o quadro de docentes da universidade.

Seria ingênuo deduzir que o fomento do poder público aos grupos periféricos se origina de uma definida política governamental. Da gestão petista no governo federal até as comissões de avaliação de projetos, passando pelo Ministério, pela presidência do órgão de cultura, pela direção do setor de artes cênicas... há uma distância que só uma diretriz estruturada e formalizada poderia transpor para generalizar uma ideologia de fomento, o que não foi o caso. Quando a Cia. Marginal recebe o prêmio para realizar seu espetáculo de estreia, outras 52 produções teatrais do estado também são agraciadas - e não há nada em comum entre elas. Além disso, a dependência da política pública por parte dos grupos teatrais não se apresenta como dado novo: já em 1993, o ator e produtor Chico Pelúcio, do Grupo Galpão, informava, no $3^{\circ}$ Encontro Brasileiro de Teatro de Grupo, que mais de $60 \%$ dos custos de seu grupo provinham das instituições públicas (TROTTA, 1995).

O que se apresenta como dado historicamente novo é a abertura inédita à produção periférica, com as mesmas exigências a que todos os projetos devem se submeter; em outras palavras, não se privilegiam extratos culturais (a não ser aqueles que dominam a escrita de projeto o que, em um país com 50 milhões de pessoas que não sabem ler e outros tantos que não sabem escrever, já é por si só uma seleção ${ }^{3}$ ). Também vale notar que, mesmo - Prêmio Miriam Muniz, único edital que mantém continuidade de 2006 a 2015,

\footnotetext{
3 Total da soma entre analfabetos e analfabetos funcionais, segundo dados do Mapa do analfabetismo no Brasil. Instituto Nacional de Estudos e Pesquisas Educacionais Anísio Teixeira (INEP). O estudo não inclui pesquisa sobre a escrita.
} 
sofre com os cortes de orçamento: se em 2006, ano de maior destinação orçamentária, ele contemplou 323 projetos no país, no ano seguinte esse número caiu para pouco mais da metade. Interrompida a gestão petista, no ano de 2015 apenas 53 projetos foram contemplados. Por isso, é possível afirmar que, mesmo o patrocínio da administração pública, os grupos periféricos se mantêm fora da hegemonia cultural.

A noção de contra hegemonia - conceito atribuído equivocadamente a Gramsci por Raimond Williams (SOUZA, 2013) fundamenta hoje 0 trabalho de organizações não-governamentais, redes transnacionais e movimentos periféricos que se contrapõem ao conceito hegemônico de político pelo investimento em poderes locais (EVANS, 2009), promovendo a multiplicação do conhecimento de tal modo que o poder se dissemine. Esse movimento, que envolve a representação política tanto de segmentos sociais identificados por gênero, etnia, religião, quanto de produtores rurais de bases ecológicas, trabalhadores e microempreendedores organizados, atinge os setores da cultura. Podemos observar esse princípio na área da produção, sob a diretriz da sustentabilidade e do financiamento comunitário, na área da organização, através da autogestão, e na criação, pela diluição de fronteiras artísticas decorrente de processos horizontais de concepção.

No teatro de que estamos tratando neste artigo, as noções de periferia e de contra hegemonia se encontram: de um lado, ele está à margem da centralidade cultural e, de outro, não se espelha no centro e se coloca como outra via. No campo da cultura e das artes, o uso do termo "periférico", que inicialmente se refere à margem geográfica das cidades, ao subúrbio, vem sendo questionado, como se contradissesse Milton Santos (em sua noção de que o centro do mundo está em todo lugar), quando, pelo contrário, o termo busca a realização política e cultural da proposição do geógrafo brasileiro. Uma manifestação cultural só pode ser contra hegemônica se, além de não se pretender central, recusa a noção de hegemonia. $E$ isso só é possível se ela se referenciar, como diz Santos, no mundo que seus olhos alcançam - nas ruas, e não nas telas. A potência dos grupos periféricos aparece hoje ligada ao propósito de não se espelhar no centro culturalmente hegemônico, mas, pelo contrário, de investir na singularidade de seus componentes, na memória do seu território, na reflexão sobre os elementos históricos da cisão entre centro e periferia.

Diversos grupos dos subúrbios e arredores da cidade vem se desenvolvendo a partir de conexões e parcerias com universidades, organizações não governamentais e apoio financeiro de órgãos de cultura, colocando em pauta a tensão entre a centralidade e seu entorno. Podemos chamar esse teatro de periférico, tendo em mente essa tensão, ou seja, entendendo que o próprio termo coloca em questão a centralização geográfica, cultural, social e política. 
A (sic) diferença do ator do campo hegemônico que pode ocupar um espaço quase exclusivamente dedicado à representação de personagens, 0 ator periférico está chamado a ser um agente cultural de outra ordem porque é praticamente impossível sobreviver exclusivamente como ator. (CARREIRA, 2006, p. 53)

O trecho acima afere que todo ator deseja ser intérprete e que, aos que não podem alcançar esse sonho universal, resta 0 trabalho cultural. $O$ autor desconsidera que: a delimitação do campo do artista de teatro em torno da representação consiste em uma limitação de sua área de atuação potencial, sendo uma restrição ao artista e à sua liberdade; esse ator restringido não tem a opção de ir além da interpretação uma vez que, no campo do mercado cultural hegemônico, as funções são estratificadas e imiscíveis; o jovem da periferia pode ser atraído para o teatro por encontrar no grupo o acolhimento de suas ansiedades, a possibilidade de criação e autoria; o ator negro pode não se interessar pela atuação junto à hegemonia do campo profissional porque não quer interpretar 0 bandido ou o serviçal, papéis mais comumente delegados a ele.

Além da periódica realização de eventos de troca artística e pedagógica, abertos à comunidade da Maré, a Cia Marginal mantém a prática de incluir no orçamento, sempre que estreia em áreas privilegiadas da cidade, o transporte de seu público, da Maré até o local de apresentação. Quando vinte jovens da Maré se inscreveram na oficina de Wallace Lino, sua motivação não foi a televisão nem as grandes produções teatrais: foi a linguagem e a projeção local do trabalho da Cia Marginal. Do projeto de difusão pedagógica realizado pela Cia Marginal em 2014, Trocas Marginais, nasce o Grupo Atiro, que, no ano seguinte, recebe apoio da Secretaria Municipal de Cultura para seu espetáculo de estreia. Constituiuse nesse processo histórico uma pequena rede teatral cujos participantes - artistas, técnicos, teóricos, espectadores - acabam de ingressar no mundo do teatro.

Planos de democratização da cultura, quase que invariavelmente ao longo da nossa história, são tentativas de transformar a classe popular em consumidora da cultura dominante. $O$ que se transformou, nos anos mais recentes da história do teatro, foi que a recíproca se tornou verdadeira: grupos periféricos, depois de formar um público novo e próprio, levaram a classe elitizada do teatro a consumir sua produção. Gerd Bornheim constataria então que existem hoje, nas periferias, teatros populares, tanto nos seus modos e meios de produção quanto em sua fruição, cuja linguagem e temática agregam novos contornos ao conceito. Mas, claro, sempre suscetíveis a mudanças políticas que, de uma hora para outra, podem não apenas retirar-lhes 0 apoio como Ihes promover uma caçada.

Os grupos, espetáculos e artistaspesquisadores abordados neste artigo como metonímia de um fenômeno que conecta periferia e universidade em consequência das ações afirmativas na cultura e na educação - revelam uma prática decolonial em que o atuante reúne arte e vida em seu empreendimento, tomando suas próprias referências como objeto artístico e/ou acadêmico. A 
decolonialidade aparece, nos casos observados, como reconhecimento da opressão, ruptura do silêncio e escrita de si. Arriscamos dizer que a possibilidade de fortalecimento do indivíduo e de seu grupo social se mostra talvez mais efetiva quando se dá, como nesses casos, pelo enfrentamento das questões e pela identificação dos modos de subalternização no presente. A academia, como o teatro, se constitui potencialmente como lugar para o exercício do diálogo e da cooperação mútua, para o avanço de uma reflexão mais profunda em relação à violência desde aquela vivenciada diariamente pelos moradores de favelas até a violência subjetiva da desqualificação do conhecimento do outro. Se a noção de "epistemologia da margem" (BENTO, 2017) refuta a existência de uma identidade comum entre os grupos excluídos, defendendo, ao contrário, a especificidade da diferença para a revelação da multiplicidade das identidades marginalizadas, a evidência dessas identidades depende da construção de redes, da efetivação de trocas. Nesse sentido, pode-se pensar em uma epistemologia decolonial no âmbito dos coletivos de produção artística, de sua formação, do compartilhamento de seus processos e da formação de seu público.

Recebido em: 05/09/2018

Aceito em 10/10/2018

\section{Referências Bibliográficas}

$\begin{array}{lrr}\text { ANATÓLIO, } & \text { Danielle. Corpo } & \text { negro } \\ \text { feminino: } & \text { ressignificação } & \text { em }\end{array}$

performances de mulheres negras. $159 f$. Dissertação (Mestrado em Artes Cênicas). Programa de Pós-Graduação em Artes Cênicas. Universidade Federal do Estado do Rio de Janeiro. Rio de Janeiro. Orientação Laura Erber. 2018.

BENTO, Berenice. Transviad@s: gênero, sexualidade e direitos humanos. Salvador: EDUFBA, 2017.

BORNHEIM, Gerd. Sobre o teatro popular. In: Encontros com a civilização brasileira, n.10. Rio de Janeiro, Civilização Brasileira, 1979.

BUTLER, Judith. Corpos que pesam: sobre os limites discursivos do sexo. In: LOURO, Guacira Lopes (org). Corpo educado: pedagogias da sexualidade. Belo Horizonte: Autêntica, 2013.

CARREIRA, André Luiz Antunes Netto. Formação de ator e teatro de grupo: periferia e busca de identidade. In: MALUF, Diab Sheila e AQUINO Ricardo Bigi de (orgs). Dramaturgia em cena. Maceió: EDUFAL, 2006.

CARVALHO, José Jorge. Inclusão étnica e racial no Brasil. São Paulo: Attar, 2005.

EVANS, P. Será possível uma globalização alternativa? Revista Periferia. Programa de Pós-Graduação em Educação, Cultura e Comunicação em Periferias Urbanas, Universidade do Estado do Rio de Janeiro, v.1, n.1, jan-jun 2009.

FERNANDES, Sílvia. Experiências do real no teatro. Sala Preta. São Paulo: Departamento de Artes Cênicas da Universidade de São Paulo, v. 13, n. 2, 2013. 
FLORENTINO, Adilson. Teatro, epistemologia e educação: crônica de um estatuto em construção. Revista OuvirOUver. Uberlândia: Universidade Federal de Uberlândia, v. 14 n. 1 , p.14-25, 2018.

FOUCAULT, Michel. Arqueologia do saber. $7^{\underline{a}}$ ed. Rio de Janeiro: Forense Universitária, 2008.

KILOMBA, Grada. Plantation Memories: Episodes of Everyday Racism. Münster: Unrast Verlag. 2. Auflage, 2010.

LINO, Wallace. O teatro como canal de ruptura do silenciamento. $84 \mathrm{f}$. Monografia (Licenciatura em Teatro). Departamento de Ensino do Teatro, Universidade Federal do Estado do Rio de Janeiro. Rio de Janeiro. Orientação Marina Henriques Coutinho. 2018.

OLIVEIRA, Luiz Fernandes de. O que é educação decolonial? Disponível em: www.academia.edu/23089659. Acesso em 08/03/2018.

PENA, S.D.J. Razões para banir o conceito de raça da medicina brasileira. História, Ciências, Saúde - Manguinhos. Rio de Janeiro: Fundação Oswaldo Cruz, v. 12, n. 1, p. 321-346, maio 2005.

RISCADO, Caio. Tese Bicha: marcas da abjeção na performance e no teatro. 196f. Tese (Doutorado em Artes Cênicas). Programa de Pós-Graduação em Artes Cênicas, Universidade Federal do Estado do Rio de Janeiro. Rio de Janeiro. Orientação Rosyane Trotta. 2018.

SANTOS, Boaventura de Sousa. Pela Mão de Alice: o social e o político na pósmodernidade. São Paulo: Cortez, 1995.
SANTOS, Boaventura de Sousa; MENESES, Maria Paula (orgs.). Epistemologias do Sul. Coimbra: Almedina, 2009.

SOUZA, Herbert Glauco de. Contrahegemonia: um conceito de Gramsci? Universidade Federal de Minas Gerais, PósGraduação em Educação, Conhecimento e Inclusão Social. Dissertação de Mestrado. Orientação de Rosemary Dore Heijmans. 2013.

TROTTA, Rosyane. Paradoxo do teatro de grupo. Rio de Janeiro, Universidade Federal do Estado do Rio de Janeiro, PósGraduação em Teatro. Dissertação de Mestrado. 1995.

TROTTA, Rosyane; PENONI, Isabel. Formação de grupo e criação coletiva na periferia do Rio de Janeiro: um relato sobre a trajetória e a escrita cênica da Cia. Marginal. In: BALTAZAR, Márcia Cristina (org). Teatro na margem. São Paulo, Hucitec, 2015. 